\title{
The diacetamidodideoxyuronic-acid-containing glycan chain of Bacillus stearothermophilus NRS 2004/3a represents the secondary cell-wall polymer of wild-type B. stearothermophilus strains
}

\author{
Christina Schäffer, ${ }^{1}$ Hanspeter Kählig, ${ }^{2}$ Rudolf Christian, ${ }^{3}$ \\ Gerhard Schulz, ${ }^{4}$ Sonja Zayni ${ }^{1}$ and Paul Messner ${ }^{1}$
}

Author for correspondence: Paul Messner. Tel: +431476 54 ext. 2202. Fax: +4314789112.

e-mail : pmessner@edv1.boku.ac.at

1 Zentrum für

Ultrastrukturforschung und Ludwig BoltzmannInstitut für Molekulare Nanotechnologie, Universität für Bodenkultur, GregorMendel-Str. 33, A-1180 Wien, Austria

2 Institut für Organische Chemie, Universität Wien, A-1090 Wien, Austria

3 Scientific Software Company, A-1140 Wien, Austria

4 Novartis Forschungsinstitut Wien, A-1235 Wien, Austria

\begin{abstract}
The diacetamidodideoxymannuronic-acid-containing glycan of Bacillus stearothermophilus NRS 2004/3a with the repeating unit structure $[\rightarrow 4)-\beta$-DManpA2,3(NAC) ${ }_{2}-(1 \rightarrow 6)-\alpha-D-G l c p-(1 \rightarrow 4)-\beta$-D-ManpA2, 3(NAC) ${ }_{2}-(1 \rightarrow 3)-\alpha-D-$ GlcpNAc- $(1 \rightarrow$ ], was examined to identify its linkage to the bacterial cell wall. In a previous paper it was suggested that this glycan is covalently linked to the surface layer (S-layer) glycoprotein of that organism. By improved chromatographic techniques (gel permeation over Sephacryl S-1000 SF; C4 reversed-phase HPLC) the diacetamidodideoxyuronic-acid-containing material was completely separated from the S-layer glycoprotein. This implicates only low, if any, specific affinity between these cell-wall components. To obtain sufficient amounts for the chemical characterization of its linkage region, the identical diacetamidodideoxyuronic-acid-containing material was isolated from sonicated cells of that organism by a purification procedure different to that for preparation of S-layers. This method allowed collection of the intact molecule including its linkage region. From the combined results of the chemical characterization and $600 \mathrm{MHz}$ NMR spectroscopy it is proposed that the diacetamidodideoxyuronic-acid-containing glycan chain, consisting of approximately six tetrasaccharide repeating units, is directly linked via a pyrophosphate bridge to carbon 6 of muramic acid residues of the peptidoglycan sacculus. About $20-25 \%$ of the muramic acid residues are substituted with these polysaccharide chains. Thus, the diacetamidodideoxyuronic-acid-containing glycan represents a secondary cellwall polymer of B. stearothermophilus NRS 2004/3a.
\end{abstract}

Keywords: Bacillus stearothermophilus, secondary cell-wall polymer, linkage region, peptidoglycan, surface layer (S-layer)

\section{INTRODUCTION}

The surface layer (S-layer) of Bacillus stearothermophilus NRS 2004/3a is composed of glycoprotein subunits. The repeating unit structure of the glycan chains was determined to be $[\rightarrow 2)-\alpha-\mathrm{L}-\mathrm{Rha} p-(1 \rightarrow 2)-\alpha-$
L-Rhap- $(1 \rightarrow 3)-\beta$-L-Rhap- $(1 \rightarrow]_{\mathrm{n} \sim 50}$ (Christian et al., 1986). In addition to the $N$-glycosidically linked Slayer glycoprotein glycans (Messner \& Sleytr, 1988a) this organism possesses cell-wall-associated carbohydrate chains. Their repeating unit structure $[\rightarrow 4)$ $\beta$-D-Man $p \mathrm{~A} 2,3(\mathrm{NAc})_{2}-(1 \rightarrow 6)-\alpha-\mathrm{D}-\mathrm{Glc} p-(1 \rightarrow 4)-$

Abbreviations: DFQ-COSY, double quantum filtered correlation spectroscopy; GARP, globally optimized alternating-phase rectangular pulses; ge, gradientenhanced; HMBC, hetero multiple bond correlation spectroscopy; HPAEC-PED, high-performance anion-exchange chromatography with pulsed electrochemical detection; HSQC, heteronuclear single quantum correlation spectroscopy; ManpA2,3(NAC) 2, 2,3-diacetamido-2,3-dideoxy-D-mannuronic acid; MurNAC, N-acetyl-D-muramic acid; NOESY, nuclear Overhauser effect spectroscopy; RP-HPLC, reversed-phase high-performance liquid chromatography; S-layer, surface layer; TFA, trifluoroacetic acid; TOCSY, total correlated spectroscopy; TPPI, time proportional phase incrementation. 
$\beta$-D-Man $p$ A2,3(NAc) $)_{2}-(1 \rightarrow 3)-\alpha$-D-Glc $p N A c-(1 \rightarrow]$ was elucidated by $250 \mathrm{MHz}$ NMR spectroscopy (Messner $e t$ al., 1987). The perception that more than one different glycan chain can be covalently linked to an S-layer protein monomer (Lechner \& Wieland, 1989) had previously led to the assumption that these carbohydrate chains might be covalently linked to the S-layer protein. However, several attempts to identify a putative carbohydrate-protein linkage region were not successful.

In previous work, the S-layer material was isolated by a standard procedure (Messner \& Sleytr, 1988b) followed by thorough proteolytic digestion of the purified S-layer glycoprotein with Pronase E. Gel filtration of the degradation products through a Bio-Gel P-30 column had completely separated the rhamnan-containing oligosaccharide fraction from the Man $p \mathrm{~A} 2,3(\mathrm{NAc})_{2}$-containing glycan chain. Neither in the NMR spectra nor in the corresponding amino acid analyses was there an indication for the presence of a covalent linkage of the $\operatorname{Man} p \mathrm{~A} 2,3$ (NAc) 2 (2,3-diacetamido-2,3-dideoxy-Dmannuronic acid)-containing glycan chain to the $\mathrm{S}$-layer protein (Messner et al., 1987). Only amino acids not involved in conventional $\mathrm{N}$-and $\mathrm{O}$-glycosidic linkages had been identified.

In this present study, we have defined the linkage type of the ManpA2,3(NAc) ${ }_{2}$-containing glycan to the cell wall of B. stearothermophilus NRS 2004/3a and investigated whether there is affinity between the S-layer glycoprotein and the coeluting ManpA2,3(NAc) ${ }_{2}$-containing glycan. Since only minor amounts of this material are present in the S-layer preparation, for the structural work on the intact molecule it was isolated from a peptidoglycan preparation of that strain.

\section{METHODS}

Growth of the bacteria. B. stearothermophilus NRS 2004/3a (Messner et al., 1984) was grown in continuous culture on modified SVIII medium $(0.5 \%$ peptone, $0.5 \%$ meat extract, $0.5 \%$ yeast extract, $0.2 \%$ glucose, $0.13 \% \mathrm{~K}_{2} \mathrm{HPO}_{4}, 0.01 \%$ $\mathrm{MgSO}_{4}, \mathrm{pH} \sim 6.9$ ) at $60^{\circ} \mathrm{C}$ with an oxygen partial pressure of $10 \%(\mathrm{v} / \mathrm{v})$ and a dilution rate of $0.2 \mathrm{~h}^{-1}$ in a 151 Biostat $\mathrm{C}$ fermenter (B. Braun). The $\mathrm{pH}$ of the culture was kept constant at a value of $\mathrm{pH} 7 \cdot 0 \pm 0.25$ by addition of $2 \mathrm{M}$ sulfuric acid. Cells were separated from culture broth by continuous centrifugation (Sepatech 17 RS contifuge, Heraeus) at $16000 \mathrm{~g}$ at $4{ }^{\circ} \mathrm{C}$. The biomass was stored at $-20^{\circ} \mathrm{C}$.

Preparation of S-layer glycoprotein. S-layer glycoprotein of $B$. stearothermophilus NRS 2004/3a was prepared according to the standard protocol (Messner \& Sleytr, 1988b).

Separation experiments. S-layer glycoprotein from $B$. stearothermophilus NRS 2004/3a was solubilized at a concentration of $30 \mathrm{mg} \mathrm{ml}^{-1}$ in $0.1 \mathrm{mM} \mathrm{NaCl}$, applied to a Sephacryl S-1000 $\mathrm{SF}$ (Pharmacia) column $(1 \times 120 \mathrm{~cm})$ and eluted with $0.1 \mathrm{mM}$ $\mathrm{NaCl}$. Fractions of $1 \mathrm{ml}$ were collected at a flow rate of $0.3 \mathrm{ml}$ $\mathrm{min}^{-1}$ and the elution profile was recorded simultaneously for carbohydrates, by a refractive index detector, and for protein, by a UV monitor at $280 \mathrm{~nm}$. Appropriate pools were assayed for quantitative carbohydrate and amino acid composition by HPAEC-PED and amino acid analysis on a Biotronik LC3000 amino acid analyser, respectively. The pool containing mainly GlcNAc, Glc and ManpA2,3(NAc) $)_{2}$ was rechromatographed under identical conditions in order to remove residual coeluting S-layer glycoprotein.

In another approach, separation between the ManpA2,3(NAc) $)_{2}$-containing glycan and the S-layer glycoprotein of $B$. stearothermophilus NRS 2004/3a was achieved on an RP-4 column (Nucleosil 300-7 RP4 I40813b, $4 \times 125 \mathrm{~mm}$; Machery \& Nagel), equilibrated with $0 \cdot 1 \%(\mathrm{v} / \mathrm{v})$ TFA in MilliQ water. For separation of the two glycan components, a linear gradient of acetonitrile was applied $(0-100 \%$ in $95 \mathrm{~min})$ at a flow rate of $1 \mathrm{ml} \mathrm{min}$. The $A_{220}$ of the eluate was monitored and the eluate was collected in $1 \mathrm{ml}$ aliquots.

Preparation of cell walls. Cells from the mid-exponential phase (wet wt, $100 \mathrm{~g}$ ) obtained by continuous cultivation of $B$. stearothermophilus NRS 2004/3a were suspended in $250 \mathrm{ml}$ cold distilled water and broken by ultrasonication using four cycles of $4 \mathrm{~min}$, each at $4^{\circ} \mathrm{C}$. The homogenate was centrifuged at $48400 \mathrm{~g}$ for $25 \mathrm{~min}$ at $4^{\circ} \mathrm{C}$. The supernatant was discarded and sedimenting broken cells were removed by gentle shaking with $1 \mathrm{M} \mathrm{NaCl}$. The remaining pellet containing whole cells was resuspended in $150 \mathrm{ml}$ cold water and repeatedly sonicated for $4 \mathrm{~min}$. Combined fractions of crude cell walls from the ultrasonication steps were collected and diluted to a total volume of $250 \mathrm{ml}$ with $1 \mathrm{M} \mathrm{NaCl}$ and centrifuged at $3020 \mathrm{~g}$ for $10 \mathrm{~min}$. Remaining debris was removed and fractions sedimenting between 3020 and $48400 \mathrm{~g}$ were collected, suspended in $200 \mathrm{ml}$ distilled water and heated at $100^{\circ} \mathrm{C}$ for $20 \mathrm{~min}$. The suspension of crude cell walls was stored frozen at $-20^{\circ} \mathrm{C}$.

Degradation of protein. After thawing, the cell-wall suspension was mixed with $250 \mathrm{ml} 2 \mathrm{M}$ sodium acetate buffer, $\mathrm{pH} 5.9$, at room temperature, incubated with $20 \mathrm{mg}$ ribonuclease at $37^{\circ} \mathrm{C}$ for $3 \mathrm{~h}$ in a rotary shaker (150 r.p.m.), and then centrifuged for $1 \mathrm{~h}$ at $17700 \mathrm{~g}$ (Araki et al., 1972). The pellet was resuspended in $200 \mathrm{ml}$ pre-warmed $50 \mathrm{mM}$ sodium phosphate buffer, $\mathrm{pH} 7 \cdot 5$, and then digested with $20 \mathrm{mg}$ trypsin for $2 \mathrm{~h}$ at $37^{\circ} \mathrm{C}$. The precipitate collected from the trypsin digest by centrifugation at $10000 \mathrm{~g}$ for $1 \mathrm{~h}$ was treated with $250 \mathrm{ml} 0.4 \%$ SDS at room temperature for $1 \mathrm{~h}$, washed six times with distilled water $(48400 \mathrm{~g}, 20 \mathrm{~min})$ and lyophilized, giving approximately $1 \mathrm{~g}$ of cell walls.

Re- $\mathrm{N}$-acetylation. Since partial de- $\mathrm{N}$-acetylation of $\mathrm{N}$-acetyl amino groups might have occurred during the previous preparation steps, re- $\mathrm{N}$-acetylation of cell walls of $B$. stearothermophilus NRS 2004/3a was cartied out by shaking $1 \mathrm{~g}$ of the sample in a solution containing $8.4 \mathrm{~g} \mathrm{NaHCO}_{3}, 5 \mathrm{ml}$ acetic acid anhydride and $100 \mathrm{ml}$ distilled water at $4{ }^{\circ} \mathrm{C}$, overnight. Then the insoluble material was collected by centrifugation $(48400 \mathrm{~g}, 20 \mathrm{~min})$, washed twice with distilled water, and lyophilized.

Lysozyme digestion. Lysozyme sensitivity of $B$. stearothermophilus NRS 2004/3a was examined by addition of $20 \mu \mathrm{l}$ enzyme $\left(1 \mathrm{mg} \mathrm{ml}^{-1}\right)$ to $2 \mathrm{ml}$ of a suspension of cells from the mid-exponential phase in $50 \mathrm{mM}$ Tris $/ \mathrm{HCl}$ buffer, $\mathrm{pH} 7 \cdot 2$. The degradation of peptidoglycan was measured by the decrease of $\mathrm{OD}_{600}$ of the sample over a time course of $90 \mathrm{~min}$. Re- $N$-acetylated cell walls (approx. $1.15 \mathrm{~g}$ ) were degraded at $37^{\circ} \mathrm{C}$ for $48 \mathrm{~h}$ in a mixture containing $130 \mathrm{mg}$ lysozyme (Sigma), $50 \mathrm{mM}$ Tris $/ \mathrm{HCl}$ buffer, $\mathrm{pH} 7 \cdot 2$ and $1 \%(\mathrm{w} / \mathrm{v})$ sodium azide in a final volume of $400 \mathrm{ml}$ (Amano et al., 1977). The lysozyme digest was concentrated to $50 \mathrm{ml}$ by evaporation at $30^{\circ} \mathrm{C}$, and dialysed (size cut-off of dialysis tubing, 12$16 \mathrm{kDa}$ ) against $5 \mathrm{l}$ distilled water. The dialysis was repeated 
five times with a total duration of $36 \mathrm{~h}$. After separation of precipitating material from the non-dialysable fraction by centrifugation, the supernatant was lyophilized giving the crude peptidoglycan preparation.

Isolation of the secondary cell-wall polymer from the peptidoglycan preparation. The lyophilized soluble fraction from the lysozyme digest was dissolved in $5 \mathrm{ml} 50 \mathrm{mM}$ $\mathrm{NH}_{4} \mathrm{HCO}_{3}$ solution and applied to an equilibrated Sephadex $\mathrm{G}-50$ column $(2.6 \times 100 \mathrm{~cm})$. The column was eluted with $50 \mathrm{mM} \mathrm{NH}_{4} \mathrm{HCO}_{3}$ at a flow rate of $2 \mathrm{ml} \mathrm{min}^{-1}$, and the elution pattern was monitored by measurement of refraction index and $A_{280}$. Fractions of $5 \mathrm{ml}$ were collected and the total elution volume was $605 \mathrm{ml}$. These fractions were assayed for rhamnose, $N$-acetylglucosamine and amino acids (Christian $e t$ al., 1993; Bock et al., 1994; Altman et al., 1996; Schäffer et al., 1996). Those giving a positive colour reaction were pooled, concentrated on a vacuum evaporator at $30^{\circ} \mathrm{C}$, dialysed five times against 31 distilled water, and lyophilized.

The polysaccharide fraction obtained by chromatography on Sephadex G-50 was further purified by reversed-phase HPLC (RP-HPLC) on a semipreparative RP-18 column (Nucleosil $120-3 \mathrm{C} 18,8 \times 125 \mathrm{~mm}$; Machery $\&$ Nagel) equipped with an RP-18 guard column (Nucleosil 120-3C18, $8 \times 40 \mathrm{~mm}$; Machery \& Nagel). The secondary cell-wall polysaccharide was separated from peptidoglycan and other contaminating proteins by using a $\mathrm{CH}_{3} \mathrm{CN} / \mathrm{H}_{2} \mathrm{O}$ gradient, containing $0 \cdot 1 \%$ TFA $\left(0-15 \% \mathrm{CH}_{3} \mathrm{CN}\right.$ for $0-45 \mathrm{~min} ; 15-100 \% \mathrm{CH}_{3} \mathrm{CN}$ for $45-47 \mathrm{~min} ; 100 \% \mathrm{CH}_{3} \mathrm{CN}$ for $47-50 \mathrm{~min} ; 100-0 \% \mathrm{CH}_{3} \mathrm{CN}$ for $50-55 \mathrm{~min} ; 0 \% \mathrm{CH}_{3} \mathrm{CN}$ for $55-60 \mathrm{~min}$ ) at a flow rate of $3 \mathrm{ml} \mathrm{min}^{-1}$. For some experiments, addition of TFA to the $\mathrm{CH}_{3} \mathrm{CN}$ gradient was omitted. Absorbance was detected at $220 \mathrm{~nm}$ and fractions of $3 \mathrm{ml}$ were collected. Fractions were combined according to the UV-elution profile and the qualitatively determined carbohydrate content. The pool containing the peptidoglycan-associated polysaccharide was finally lyophilized, yielding approximately $165 \mathrm{mg}$ of secondary cell-wall polymer.

For the NMR experiments (see Table 1) the following preparations were used : preparation I $\left(9 \cdot 1 \mathrm{mg}\right.$ per $\left.\mathrm{ml} \mathrm{D}_{2} \mathrm{O}\right)-$ secondary cell-wall polymer, purified by RP-HPLC in the presence of TFA in the $\mathrm{CH}_{3} \mathrm{CN}$ gradient (retention interval 20-27 $\mathrm{min})$; preparation II (21.0 $\mathrm{mg}$ per $\left.\mathrm{ml} \mathrm{D}_{2} \mathrm{O}\right)$ - secondary cell-wall polymer, purified by RP-HPLC without addition of TFA to the gradient (retention interval 3-15 min); preparation III ( $5.0 \mathrm{mg}$ per $\left.\mathrm{ml} \mathrm{D}_{2} \mathrm{O}\right)$ - during purification of preparation II the material eluting from the column at $47-49 \mathrm{~min}$ was rechromatographed on the same RP-HPLC system using a modified $\mathrm{CH}_{3} \mathrm{CN}$ gradient of $0-100 \%$ in $95 \mathrm{~min}$. The material eluting at 11-18 min was collected and lyophilized. By amino acid analysis and HPAEC-PED it was demonstrated that it represented the cleaved pure peptidoglycan portion of that complex.

NMR experiments. The ${ }^{13} \mathrm{C}$ NMR spectra $(100.62 \mathrm{MHz}$, attached proton test) were recorded on a BRUKER Avance DRX 400 WB NMR spectrometer equipped with a ${ }^{1} \mathrm{H},{ }^{13} \mathrm{C}$ observe dual probe. All other spectra were recorded with a BRUKER Avance DRX 600 NMR spectrometer using either a $5 \mathrm{~mm}$ broadband inverse probe with $z$-gradients or a $5 \mathrm{~mm}$ triple probe $\left({ }^{1} \mathrm{H},{ }^{13} \mathrm{C}\right.$, broadband) with $x, y, z$-gradients at frequencies for ${ }^{1} \mathrm{H}$ at $600 \cdot 13 \mathrm{MHz}$, for ${ }^{13} \mathrm{C}$ at $150 \cdot 90 \mathrm{MHz}$, and for ${ }^{31} \mathrm{P}$ at $242.94 \mathrm{MHz}$, respectively. A series of the following experiments were performed for the samples in $\mathrm{D}_{2} \mathrm{O}$ solution.

Double quantum filtered correlation spectroscopy (DQFCOSY) with gradient coherence selection according to the scheme of Davis et al. (1991) [2048 data points in $\mathrm{f}_{2}, 512$ data points in $\mathrm{f}_{1}$, sweep width $3000 \mathrm{~Hz}, 1 \mathrm{~ms}$ sine-shaped gradient pulses with $20 \%$ maximum amplitude, absorption mode in $f_{1}$ using time proportional phase incrementation (TPPI)]; total correlated spectroscopy (TOCSY) with 3-9-19 WATERGATE (Piotto et al., 1992; Sklenar et al., 1993) solvent suppression (2048 data points in $f_{2}, 512$ data points in $f_{1}$, sweep width $4500 \mathrm{~Hz}, 120 \mathrm{~ms} \mathrm{MLEV} 17$ spin lock, $1 \mathrm{~ms}$ sine-shaped gradient pulses with $20 \%$ maximum amplitude, absorption mode in $\mathrm{f}_{1}$ using TPPI); nuclear Overhauser effect spectroscopy (NOESY) with 3-9-19 WATERGATE (2048 data points in $f_{2}$, 512 data points in $f_{1}$, sweep width $4500 \mathrm{~Hz}, 150-500 \mathrm{~ms}$ mixing time, $1 \mathrm{~ms}$ sine-shaped gradient pulses with $20 \%$ maximum amplitude, absorption mode in $f_{1}$ using TPPI); sensitivity enhanced ${ }^{1} \mathrm{H},{ }^{13} \mathrm{C}$-HSQC with echo/anti-echo selection (Kay et al., 1992; Schleucher $e$ al., 1994) (2048 data points and $3000 \mathrm{~Hz}$ sweep width in $\mathrm{f}_{2}, 256$ data points and $15000 \mathrm{~Hz}$ sweep width in $f_{1}, 1$ ms sine shaped gradient pulses with $80 \%$ maximum amplitude, globally optimized alternating-phase rectangular pulses (GARP) ${ }^{13} \mathrm{C}$ decoupling during acquisition, optimized on $\mathrm{CH}$ groups); gradient selected ${ }^{1} \mathrm{H},{ }^{13} \mathrm{C}-\mathrm{HMBC}$ (hetero multiple bond correlation spectroscopy) (Hurd \& John, 1991) with and without a low-pass J-filter (2048 data points and $3000 \mathrm{~Hz}$ sweep width in $\mathrm{f}_{2}, 512$ data points and $27150 \mathrm{~Hz}$ sweep width in $\mathrm{f}_{1}, 1 \mathrm{~ms}$ sine-shaped gradient pulses with $50 \%$ maximum amplitude, long-range coupling 5 or $6 \mathrm{~Hz}$ ).

In addition for the samples in $90 \% \mathrm{H}_{2} \mathrm{O} / 10 \% \mathrm{D}_{2} \mathrm{O}$ the DQFCOSY and the experiments using the 3-9-19 WATERGATE solvent suppression scheme were recorded applying magic angle gradients (van Zijl et al., 1995) with $1 \mathrm{~ms}$ sine-shaped gradients of equal amplitude along every axis and a maximum amplitude of $40 \%$ in one direction.

Experiments using ${ }^{31} \mathrm{P}$ frequency include direct observed phosphorus NMR spectra with proton decoupling, ${ }^{1} \mathrm{H}$ NMR spectra with ${ }^{31} \mathrm{P}$ GARP decoupling and two-dimensional gradient selected ${ }^{1} \mathrm{H}^{31} \mathrm{P}-\mathrm{HMBC}$ spectra (Hurd \& John, 1991).

All the processing was done off line on Silicon Graphics workstations using the BRUKER software XWIN-NMR 2.0. All two-dimensional spectra were zerofilled in $\mathrm{f}_{\mathbf{1}}$ doubling the data points and multiplied in both dimensions with a $90^{\circ}$. shifted square sine window function. The spectra were phase corrected in absorption mode in both dimensions except the HMBC spectra, which were calculated to magnitude mode. In addition to the BRUKER software, for the analysis the programs PRONTO 970306 (provided by M. Kjaer, F. M. Poulsen and the Carlsberg Research Center, Copenhagen, Denmark) and AZARA 2.0 (provided by W. Boucher and the Department of Biochemistry, University of Cambridge, UK) were used also on Silicon Graphics workstations.

\section{RESULTS}

\section{Preparation of the S-layer glycoprotein}

The S-layer glycoprotein of B. stearothermophilus NRS $2004 / 3$ a was prepared by the standard purification procedure (Messner \& Sleytr, 1988b) including removal of the cytoplasmic membrane by treatment with Triton $\mathrm{X}-100$ and extraction of the S-layer glycoprotein using $5 \mathrm{M}$ guanidine hydrochloride. Carbohydrate composition of that material, as determined by HPAEC-PED, revealed a total rhamnose content of $185 \mathrm{nmol}$ (mg Slayer glycoprotein $)^{-1}(\sim 4.5 \%, \mathrm{w} / \mathrm{w})$, originating from the rhamnan S-layer glycan, and 8 nmol each of GlcNAc and Glc per mg, indicating the presence of trace amounts 
$(\sim 0.5 \%, w / w)$ of ManpA2,3(NAc) $)_{2}$-containing glycan (Messner et al., 1987).

\section{Separation of the ManpA2,3(NAc) ${ }_{2}$-containing glycan from S-layer glycoprotein}

To prove that the ManpA2,3(NAc) ${ }_{2}$-containing glycan chains are not covalently linked to the S-layer glycoprotein of B. stearothermophilus NRS 2004/3a, separation experiments using improved chromatographic techniques were performed. S-layer glycoprotein prepared by the standard purification procedure was subjected to gel filtration on a Sephacryl S-1000 SF column; this resulted, after rechromatography of the appropriate pool, in a complete separation of the intact high-molecular-mass S-layer glycoprotein with the glycosidically bound rhamnan, and a peak of lower apparent molecular mass representing the Man $p$ A2,3(NAc) ${ }_{2}$-containing material. Amino acid analysis of the latter pool revealed GlcNAc and a substance which showed the retention time of histidine as constituents. In the previous study (Messner et al., 1987) this material had been identified as ManpA2,3(NAc) ${ }_{2}$. Additionally, the presence of the constituents GlcNAc and Glc and of trace amounts of ManNAc was confirmed by HPAEC-PED.

Separation of the Man $p$ A2,3(NAc) ${ }_{2}$-containing material from the $S$-layer glycoprotein was also performed by RP-HPLC on an RP4 column with a $\mathrm{CH}_{3} \mathrm{CN}-\mathrm{TFA}$ gradient. The Man $p$ A2,3(NAc) ${ }_{2}$-containing glycan eluted at a $\mathrm{CH}_{3} \mathrm{CN}$ concentration of approximately $31 \%(\mathrm{v} / \mathrm{v})$, whereas the S-layer glycoprotein was collected in the gradient at $45 \% \mathrm{CH}_{3} \mathrm{CN}$, demonstrating that there is no covalent linkage of this glycan-containing material to the S-layer glycoprotein. This result supports the observation from the gel-permeation chromatography experiment.

\section{Isolation of the ManpA2,3(NAc) $)_{2}$-containing glycan from peptidoglycan}

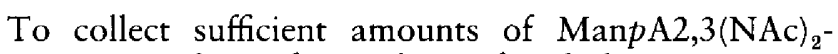
containing glycan for analysis of its linkage region we changed the purification strategy for this polysaccharide fraction. The currently used modified procedure essentially follows the method of Araki et al. (1972). After isolation of the cell walls, to which the Man $p \mathrm{~A} 2,3(\mathrm{NAc})_{2}$-containing glycan is still attached, the preparation was incubated for $48 \mathrm{~h}$ at $37^{\circ} \mathrm{C}$ with lysozyme (Amano et al., 1977) to break down the peptidoglycan sacculus completely. The reaction mixture was subjected to gel filtration on a Sephadex G-50 column and appropriate polysaccharide-containing fractions were collected. Further purification was performed by $\mathrm{HPLC}$ using a $\mathrm{CH}_{3} \mathrm{CN}$ gradient, containing $0.1 \%(\mathrm{v} / \mathrm{v})$ TFA for improved separation. Omission of TFA in the HPLC gradient gave poorer resolution but higher recovery of the intact cell-wall polymerpeptidoglycan complex (Fig. 1). Appropriate fractions were collected and examined by HPAEC-PED and amino acid analysis. Quantification showed that
$20-25 \%$ of the MurNAc residues were randomly substituted with the ManpA2,3(NAc) ${ }_{2}$-containing polysaccharide. These fractions were subjected to NMR analysis (for details see Methods).

\section{NMR characterization of the secondary cell-wall polymer}

The glycan structure was derived from one- and twodimensional NMR experiments recorded on a 400 and a $600 \mathrm{MHz}$ spectrometer. The structure of the repeating unit was confirmed to consist of four sugars in the described arrangement (Messner et al,, 1987). Since chemical shift values and line width of the observed NMR signals showed a strong $\mathrm{pH}$ dependence, the reinvestigation of the glycan was performed at two different $\mathrm{pH}$ values. At low $\mathrm{pH}$ values $(\sim \mathrm{pH} 2.0)$ the proton signals were sharp and the anomeric region was well resolved. At higher $\mathrm{pH}$ values $(\sim \mathrm{pH} 3.5)$, however, the signal half width increased and Glc $p$ and GlcpNAc anomeric protons of the polysaccharide chain overlapped. In the ${ }^{13} \mathrm{C}$ NMR spectra, particularly the C-5 and C-6 signals of the $\mathrm{Man} p \mathrm{~A} 2,3(\mathrm{NAc})_{2}$ units were shifted. In addition to the reinvestigated and completed ${ }^{13} \mathrm{C}$ chemical shift data, an assignment of the ${ }^{1} \mathrm{H}$ spin systems was possible by gradient-enhanced (ge) homoand heteronuclear two-dimensional NMR experiments (Table 1). The glycosidic linkages were confirmed from ge-HMBC experiments by means of three-bond correlation of the anomeric protons to the glycosidic bond carbons and vice versa, thus providing a non-empirical verification of the reported sequence.

Starting from the proton chemical shift data (Table 1, Fig. 2) of the anomeric proton from sugar $\mathbf{A}$ an additional cross-peak at lower intensity could be identified in the DQF-COSY experiment. Eventually it led to a complete set of ${ }^{1} \mathrm{H}$ and ${ }^{13} \mathrm{C}$ signals belonging to a Man $p$ A2,3(NAc) $)_{2}$ residue which showed significant chemical shift differences for the ${ }^{1} \mathrm{H}$ signals in positions 2 to 5 and especially the ${ }^{13} \mathrm{C}$ signal of $\mathrm{C}-4$. The observed upfield shift at the $\mathrm{C}-4{ }^{13} \mathrm{C}$ shift value, as well as the $\mathrm{H}$ 4 of that Man $p \mathrm{~A} 2,3(\mathrm{NAc})_{2}$ unit $\mathbf{A}^{\prime}$, confirmed this unit as the terminal sugar at the non-reducing end of the polysaccharide chain. Integration of the well-resolved cross-peaks in the HSQC experiment (Fig. 3) for this terminal sugar and comparison with the cross-peak volume of the corresponding signals in the polysaccharide chain showed a ratio of approximately $1: 5$, indicating a chain length of approximately six repeating units.

To identify the linkage region between the repeating units and the peptidoglycan present in the sample, proton spectra were recorded with simultaneous ${ }^{31} \mathrm{P}$ decoupling to detect signals of phosphorylated sugars. In the anomeric region at approximately 5.43 p.p.m. a collapse of a doublet splitting $\left({ }^{3} J_{\mathrm{H}, \mathrm{p}} \sim 6 \mathrm{~Hz}\right)$ could be seen in preparation I (see Methods for the different preparations). In preparation II a significant reduction of the line width for the signal at the same chemical shift was observed. A direct ${ }^{31} \mathrm{P}$ spectrum with proton 


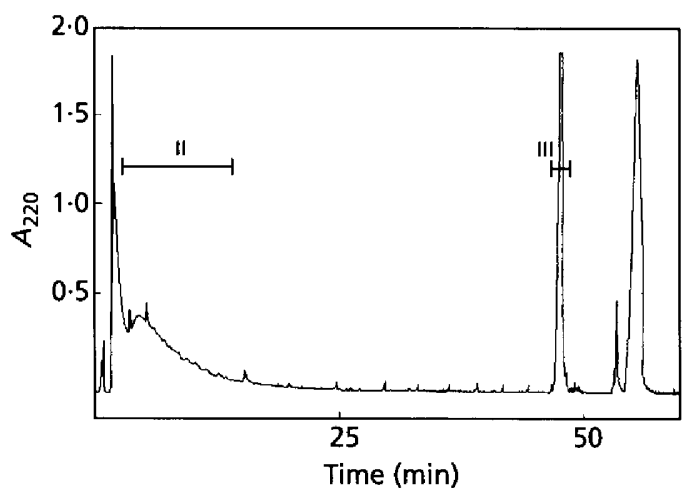

Fig. 1. Final purification of the secondary cell-wall polymer from B. stearothermophilus NRS 2004/3a by RP-HPLC on a semipreparative RP-18 column using a $\mathrm{CH}_{3} \mathrm{CN} / \mathrm{H}_{2} \mathrm{O}$ gradient without TFA.

decoupling gave two signals, at 1.33 and -0.69 p.p.m., respectively, in agreement for a diphosphate bridge.

Analysis of the whole spin system starting from this phosphorylated anomeric signal at 5.43 p.p.m. showed the unit designated $D^{\prime}$ to be an $\alpha \mathrm{GlcNAc}$ residue which, based on the carbon chemical shifts, was substituted in position 3. Due to the low intensity of the signals for this unit, further investigation was a very tedious task. To resolve the spectral overlap, experiments were performed in $90 \% \mathrm{H}_{2} \mathrm{O} / 10 \% \mathrm{D}_{2} \mathrm{O}$ solution (Fig. 4). As the whole system contained a number of amino sugars, additional information could be gained by NMR experiments in $\mathrm{H}_{2} \mathrm{O}$ from the slowly exchanging $\mathrm{NH}$ signals in a chemical shift region far from the carbohydrate signals. In a NOESY spectrum with suppression of water signal by a 3-9-19 WATERGATE sequence, a cross peak could be identified starting from the $\mathrm{NH}$ signal of the phosphorylated GlcNAc to an anomeric proton of another sugar, again implying a $1 \rightarrow 3$ linkage. This new sugar was an amino sugar with an NHAc group in position 2. Based on the recorded anomeric one-bond $\mathrm{CH}$ coupling constant of $163 \mathrm{~Hz}$ and a small $<2 \mathrm{~Hz}$ ${ }^{3} J_{\mathrm{H}, \mathrm{H}}$ coupling constant of this sugar, a manno system carrying at least one NHAc group in position 2 can be supposed. Since the whole spin system could not be identified, no linkage information to the polysaccharide chain is available. However, since the chemical shift values observed for this unit designated $C^{\prime}$ are almost indistinguishable from that of unit $\mathrm{C}$, it is fair to assume that units $\mathbf{C}^{\prime}$ and $\mathbf{D}^{\prime}$ belong to a repeating unit linked via pyrophosphate, thus indicating a blockwise attachment of the polysaccharide chain.

Continuing the NMR analysis from the phosphorylated anomeric signal towards the reducing end, a twodimensional ${ }^{1} \mathrm{H},{ }^{31} \mathrm{P}$ HMBC spectrum was recorded showing signals at two different phosphorus frequencies. In addition to the anomeric proton and $\mathrm{H}-2$ from the $\alpha \mathrm{Glc} p \mathrm{NAc}$ unit $\mathrm{D}^{\prime}$ at $\delta\left({ }^{31} \mathrm{P}\right)=1.33$ p.p.m. a signal set for two protons characteristic for a $\mathrm{CH}_{2}$ group was detected $\left[\delta\left({ }^{1} \mathrm{H}\right)=4.073\right.$ and 3.994 p.p.m., $\delta\left({ }^{31} \mathrm{P}\right)=$
-0.69 p.p.m.], implying a linkage to a C-6, most probably of a muramic acid residue. Due to limitations in sensitivity (broad signals and additional ${ }^{1} \mathrm{H},{ }^{31} \mathrm{P}$ couplings) no direct connection from this $\mathrm{H}-6$ to $\mathrm{H}-5$ or $\mathrm{C}-5$ of $\alpha / \beta$ MurNAc could be established. However, considering the different shifts of protons 4,5 and 6 of $\alpha / \beta$ MurNAc in the intact polysaccharide-peptidoglycan preparation (Table 1, preparation II) to those shifts of the peptidoglycan alone (preparation III) indicates MurNAc to be phosphorylated in position 6 in the intact cell-wall polymer.

The signals belonging to the peptidoglycan moiety were visible in all spectra and were identified by comparison to spectra from the separated peptidoglycan portion alone. A detailed structural analysis of this part of the sample by NMR analysis was impossible due to the inherent heterogeneity of the sample. In about $60 \%$ of the intact cell-wall polymer (preparation II), the oligosaccharide-carrying glycan strands of the peptidoglycan consisted of disaccharide $\beta$-GlcNAc- $(1 \rightarrow 4)-\alpha / \beta$ MurNAc units. The rest contained larger fragments of the peptidoglycan saccharide strands (multiples of the disaccharide units in a random order; see Fig. 2). No attempts were made to assign every single signal from the peptidoglycan portion. A partial assignment of the peptidoglycan moiety was facilitated by comparison to reported values of synthetic models (Kantoci et al., 1989). Alanine, glutamine and diaminopimelic acid were again assigned using ge-TOCSY, ge-DQF-COSY and ge-HSQC spectra. The peptide sequence of the sample was compatible with that of the Bacillus peptidoglycan chemotype A1 $\gamma$ (Schleifer \& Kandler, 1972; Archibald, 1989).

\section{DISCUSSION}

The walls of Gram-positive bacteria usually contain peptidoglycan and different accessory polymers such as teichoic acids, teichuronic acids, neutral or charged polysaccharides, proteins (e.g. S-layer proteins), and in some cases even covalently bound lipids (for review see Archibald, 1989). Teichoic acid and teichuronic acid are covalently linked to the peptidoglycan throughout the thickness of the wall (Ward, 1981). Teichoic acids contain charged phosphate groups and, often, charged amino acid groups whereas teichuronic acids contain charged carboxyl groups. Although they are often described as accessory or secondary wall polymers, their presence is required for the ordered assembly of wall material and for normal wall function. Due to their functional groups they contribute to the overall surface charge of the cells and also to specific surface properties (for reviews see Ward, 1981; Hancock, 1991).

For several Bacillus strains, secondary cell-wall polymers which contain cores with the structure $[\rightarrow 3)$ $\beta$-D-Man $p$ NAc- $(1 \rightarrow 4)-\beta$-D-GlcpNAc- $(1 \rightarrow]$, connecting the oligosaccharide chain to the pyrophosphate group, have been described (Kaya et al., 1984; Kojima et al., 1985, 1988; Araki \& Ito, 1989). Similar cores were also found in typical ribitol and glycerol teichoic acids of 
Table 1. ${ }^{1} \mathrm{H}$ and ${ }^{13} \mathrm{C}$ NMR chemical shift data (in p.p.m.) of the diacetamidodideoxyuronic-acid-containing glycan chain and the linkage region of $B$. stearothermophilus

For each preparation (I, II, III), the first row shows chemical shift data for ${ }^{1} \mathrm{H}$ relative to external acetone $(\delta=2 \cdot 225 \mathrm{p} . \mathrm{p} . \mathrm{m}$. $)$ and the second row shows chemical shift data for ${ }^{13} \mathrm{C}$ relative to external dioxane $(\delta=67 \cdot 40$ p.p.m.). All data were acquired at $300 \mathrm{~K}$.

Numbers in parentheses represent ${ }^{1} J_{\mathrm{H}}$ coupling constants in Hz. I, preparation I from HPLC separation with $0.1 \%(\mathrm{v} / \mathrm{v})$ TFA in the

$\mathrm{CH}_{3} \mathrm{CN}$ elution gradient $(6.4 \mathrm{mg}$ in $0.7 \mathrm{ml} \mathrm{D} 2 \mathrm{O}, \mathrm{pH}=2.11)$; II, preparation II from HPLC separation without TFA (14.7 mg in $0.7 \mathrm{ml}$ $\left.\mathrm{D}_{2} \mathrm{O}, \mathrm{pH}=3.32\right)$; III, preparation III containing only the peptidoglycan portion $\left(3.5 \mathrm{mg}\right.$ in $\left.0.7 \mathrm{ml} \mathrm{D}_{2} \mathrm{O}, \mathrm{pH}=4.10\right)$.

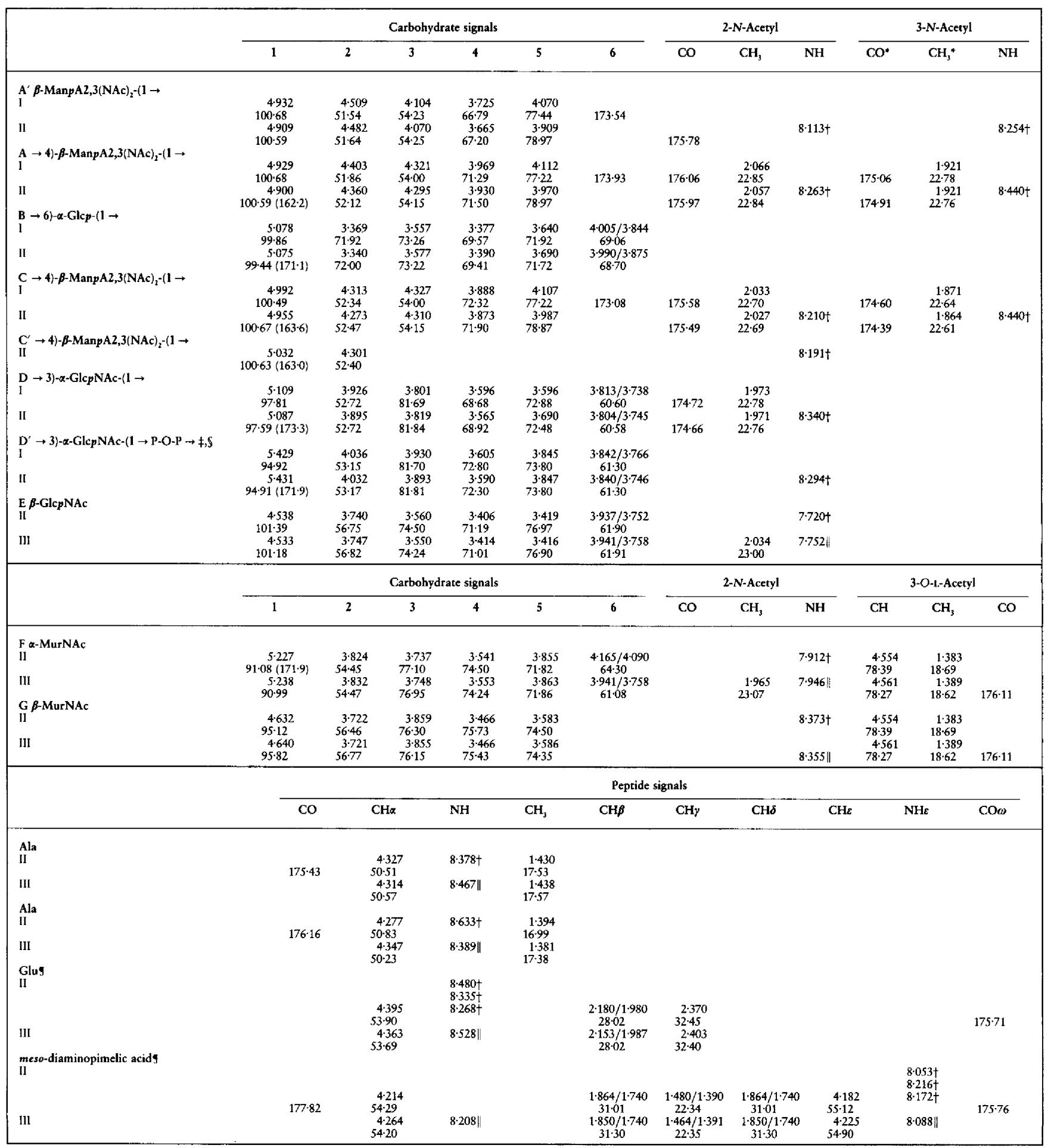

*Assignments interchangeable. †Preparation Il in $0.7 \mathrm{ml} 90 \%(\mathrm{v} / \mathrm{v}) \mathrm{H}_{2} \mathrm{O} / 10 \%(\mathrm{v} / \mathrm{v}) \mathrm{D}_{2} \mathrm{O}$.

$\ddagger \delta\left({ }^{31} \mathrm{P}\right)=1.33$ p.p.m. and -0.69 p.p.m. (relative to external $80 \% \mathrm{H}_{3} \mathrm{PO}_{4}, \delta=0$ p.p.m.).

$\$$ Connected to a $\mathrm{CH}_{2}$ group $\left[\delta\left({ }^{1} \mathrm{H}\right)=4.073,3.994\right.$ p.p.m. $]$ in preparation $\mathrm{I}$.

|| Preparation III in $0.7 \mathrm{ml} 90 \%$ (v/v) $\mathrm{H}_{2} \mathrm{O} / 10 \%$ (v/v) $\mathrm{D}_{2} \mathrm{O}$.

I $\delta$ values approximately, belonging to more than one residue. 


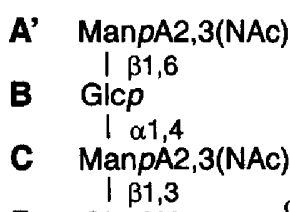

D GIcpNAC

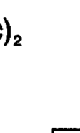
)$_{2}$

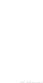

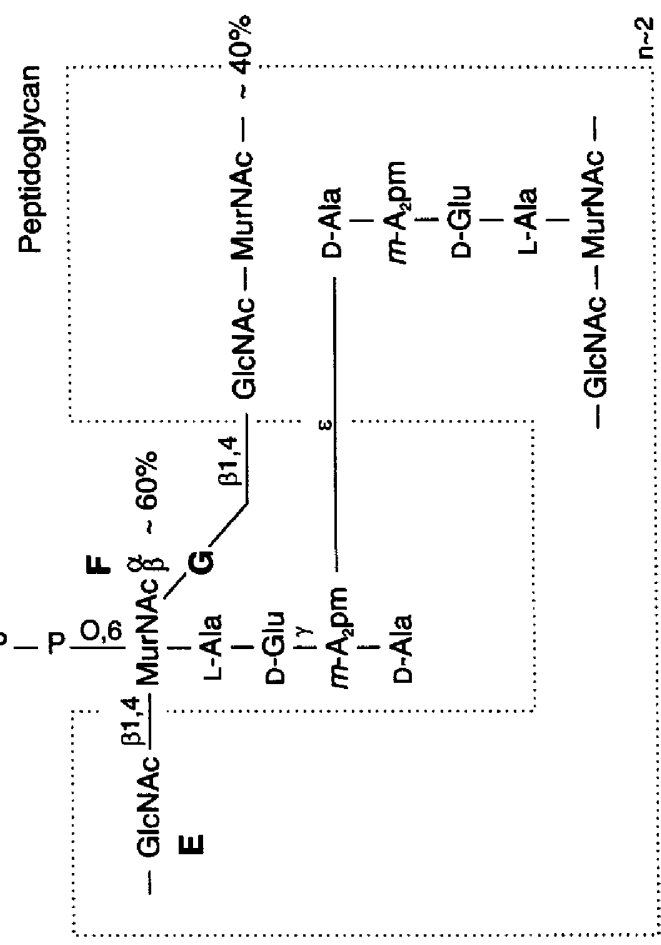

Fig. 2. Proposed structure of the secondary cell-wall polymer-peptidoglycan complex. The capital letters indicate the appropriate units according to the assignment from the NMR experiments.

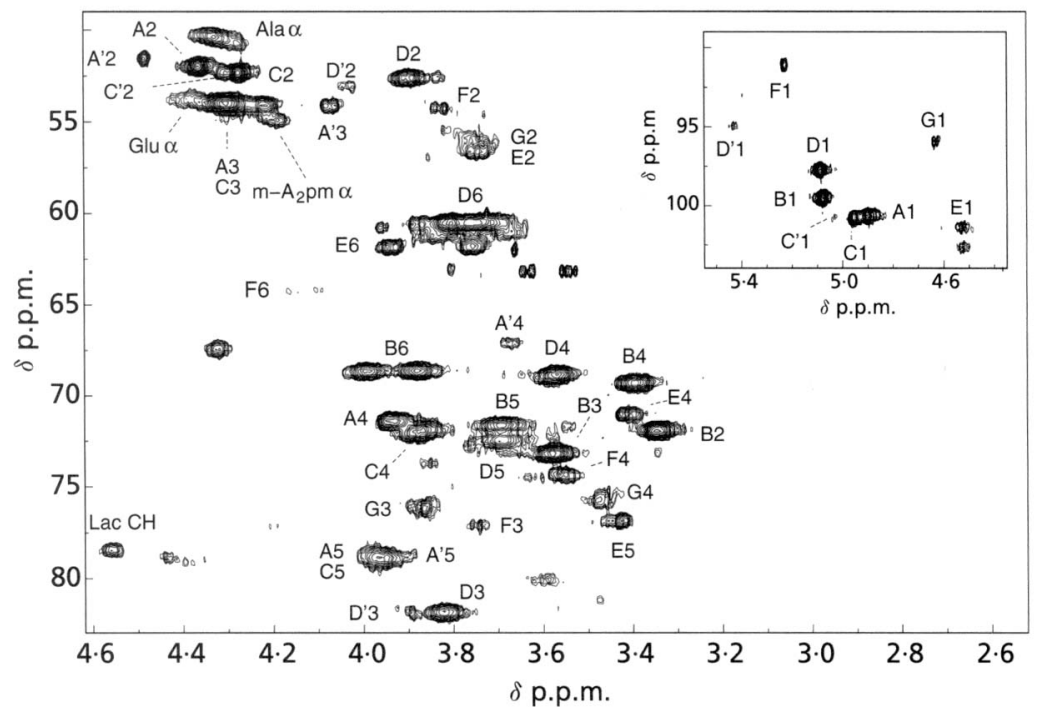

Fig. 3. ${ }^{1} \mathrm{H},{ }^{13} \mathrm{C}-$ ge-HSQC NMR spectrum of preparation II, core region and (inset) anomeric region.
Gram-positive organisms (for reviews see Munson \& Glaser, 1981; Archibald, 1989). From the combined data of the structural and chemical characterization of the secondary cell-wall polymer of strain $B$. stearothermophilus NRS 2004/3a it can be concluded that the $\operatorname{Man} p A 2,3(\mathrm{NAc})_{2}$-containing saccharide chains, which on average are composed of approximately six identical repeating units (Messner et al., 1987), are linked via pyrophosphate bridges to about $20-25 \%$ of the muramic acid residues of the peptidoglycan sacculus (Fig. 2). Although during the chemical characterization of the secondary cell-wall polymer of $B$. stearothermophilus NRS 2004/3a, GlcNAc and trace amounts of ManNAc have been determined, the NMR data do not support the presence of a ManNAc $\rightarrow$ GlcNAc core disaccharide in this organism. On the other hand, its existence cannot 


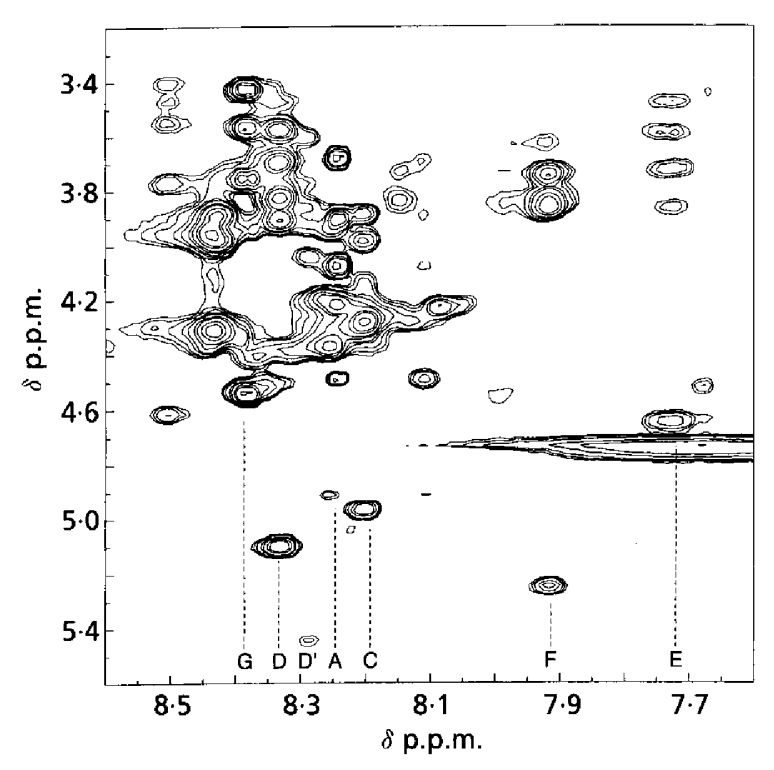

Fig. 4. TOCSY NMR spectrum (3-9-19 WATERGATE solvent suppression) of preparation II in $90 \% \mathrm{H}_{2} \mathrm{O} / 10 \% \mathrm{D}_{2} \mathrm{O}$, amide region.

be ruled out completely because the first two components of the repeating unit are GlcNAc and a mannosugar system which would be similar to the signals for the postulated core in the NMR experiments (see Table 1). The existence of a comparable core disaccharide consisting of GlcNAc and ManpA2,3(NAc) $)_{2}$ residues has been suggested in a preliminary report on an acidic cell-wall polysaccharide of Propionibacterium acnes (Nagaoka et al., 1985), however, without further substantiation.

The identified linkage region of the $\operatorname{Man} p \mathrm{~A} 2,3(\mathrm{NAc})_{2}{ }^{-}$ containing glycan, together with the observation that this glycoconjugate can be separated from the S-layer glycoprotein by improved chromatographic techniques, clearly demonstrates that this glycoconjugate is not covalently linked to the S-layer glycoprotein. It shows that there is only low, if any, specific affinity of the secondary cell-wall polymer to the intact S-layer protein. This observation is supported by the previous separation experiments of proteolytically degraded S-layer glycoprotein preparations, which resulted in a complete splitting of both carbohydrate structures (Messner et al., 1987). Thus, our previous assumption of a possible glycoprotein nature of the $\operatorname{Man} p \mathrm{~A} 2,3(\mathrm{NAc})_{2}$-containing glycoconjugate should be changed.

In conclusion, this glycoconjugate represents a secondary cell-wall polymer of $B$. stearothermophilus NRS $2004 / 3 \mathrm{a}$; this has also been observed with other $B$. stearothermophilus strains (Ries et al., 1997; Egelseer et al., 1998). Possible biological functions of this type of cell-wall constituent in bacilli have been recently discussed in the context of mediating binding of the S-layer to the peptidoglycan sacculus (Egelseer et al., 1998; Sára et al., 1998). Comparable functional analyses have not been performed with the secondary cell-wall polymer of B. stearothermophilus NRS 2004/3a.

\section{ACKNOWLEDGEMENTS}

We thank Andrea Scheberl for help with the purification of the specimens. This work was supported by the Austrian Science Fund, project S7201-MOB (to P. M.) and the Federal Ministry of Science and Transportation.

\section{REFERENCES}

Altman, E., Schäffer, C., Brisson, J.-R. \& Messner, P. (1996). Isolation and characterization of an amino sugar-rich glycopeptide from the surface layer glycoprotein of Thermoanaerobacterium thermosaccharolyticum E207-71. Carbobydr Res 295, 245-253.

Amano, K., Hazama, S., Araki, Y. \& Ito, E. (1977). Isolation and characterization of structural components of Bacillus cereus AHU 1356 cell walls. Eur J Biochem 75, 513-522.

Araki, Y. \& Ito, E. (1989). Linkage units in cell walls of Grampositive bacteria. Crit Rev Microbiol 17, 121-135.

Araki, Y., Nakatani, T., Nakayama, K. \& Ito, E. (1972). Occurrence of $N$-nonsubstituted glucosamine residues in peptidoglycan of lysozyme-resistant cell walls from Bacillus cereus. J Biol Chem 247, 6312-6322.

Archibald, A. R. (1989). The Bacillus cell envelope. In Bacillus: Biotechnology Handbooks, vol 2, pp. 217-254. Edited by C. R. Harwood. New York: Plenum.

Bock, K., Schuster-Kolbe, J., Altman, E., Allmaier, G., Stahl, B., Christian, R., Sleytr, U. B. \& Messner, P. (1994). Primary structure of the O-glycosidically linked glycan chain of the crystalline surface layer glycoprotein of Thermoanaerobacter thermohydrosulfuricus L111-69: galactosyl tyrosine as a novel linkage unit. J Biol Chem 269, 7137-7144.

Christian, R., Schulz, G., Unger, F. M., Messner, P., Küpcü, Z. \& Sleytr, U. B. (1986). Structure of a rhamnan from the surface layer glycoprotein of Bacillus stearothermophilus strain NRS 2004/3a. Carbobydr Res 150, 265-272.

Christian, R., Schulz, G., Schuster-Kolbe, J., Allmaier, G., Schmid, E. R., Sleytr, U. B. \& Messner, P. (1993). Complete structure of the tyrosine-linked saccharide moiety from the surface layer glycoprotein of Clostridium thermobydrosulfuricum \$102-70. $J$ Bacteriol 175, 1250-1256.

Davis, A. L., Laue, E. D., Keeler, J., Moskau, D. \& Lohman, J. (1991). Absorption-mode 2-dimensional NMR spectra recorded using pulsed field gradients. J Magn Reson 94, 637-644.

Egelseer, E., Leitner, K., Jarosch, M., Hotzy, C., Zayni, S., Sleytr, U. B. \& Sára, M. (1998). The S-layer proteins of two Bacillus stearothermophilus wild-type strains are bound via their $\mathrm{N}$ terminal region to a secondary cell wall polymer of identical chemical composition. J Bacteriol 180, 1488-1495.

Hancock, I. C. (1991). Microbial cell surface architecture. In Microbial Cell Surface Analysis: Structural and Physicochemical Methods, pp. 21-59. Edited by N. Mozes, P. S. Handley, H. J. Busscher \& P. G. Rouxhet. New York: VCH.

Hurd, R. E. \& John, B. K. (1991). Gradient-enhanced protondetected heteronuclear multiple-quantum coherence spectroscopy. J Magn Reson 91, 648-653.

Kantoci, D., Keglević, D. \& Derome, A. E. (1989). Convenient synthesis of $O$-(2-acetamido-2-deoxy- $\beta$-D-glucopyranosyl $)-(1 \rightarrow 6$ and 4)-N-acetylmuramoyl-L-alanyl-D-isoglutamine. Carbohydr Res 186, 77-85. 
Kay, L. E., Keifer, P. \& Saarinen, T. (1992). Pure absorption gradient enhanced heteronuclear single quantum correlation spectroscopy with improved sensitivity. J Am Chem Soc 114, 10663-10665.

Kaya, S., Yokoyama, K., Araki, Y. \& Ito, E. (1984). NAcetylmannosaminyl(1-4) $N$-acetylglucosamine, a linkage unit between glycerol teichoic acid and peptidoglycan in cell walls of several Bacillus strains. J Bacteriol 158, 990-996.

Kojima, N., Araki, Y. \& Ito, E. (1985). Structure of the linkage units between ribitol teichoic acids and peptidoglycan. J Bacteriol 161, 299-306.

Kojima, N., Kaya, S., Araki, Y. \& Ito, E. (1988). Pyruvic-acidcontaining polysaccharide in the cell wall of Bacillus polymyxa AHU 1385. Eur J Biochem 174, 255-260.

Lechner, J. \& Wieland, F. (1989). Structure and biosynthesis of prokaryotic glycoproteins. Annu Rev Biochem 58, 173-194.

Messner, P. \& Sleytr, U. B. (1988a). Asparaginyl-rhamnose: a novel type of protein-carbohydrate linkage in a eubacterial surface-layer glycoprotein. FEBS Lett 228, 317-320.

Messner, P. \& Sleytr, U. B. (1988b). Separation and purification of S-layers from Gram-positive and Gram-negative bacteria. In Bacterial Cell Surface Techniques, pp. 97-104. Edited by I. C. Hancock \& I. R. Poxton. Chichester: Wiley.

Messner, P., Hollaus, F. \& Sleytr, U. B. (1984). Paracrystalline cell wall surface layers of different Bacillus stearothermophilus strains. Int J Syst Bacteriol 34, 202-210.

Messner, P., Sleytr, U. B., Christian, R., Schulz, G. \& Unger, F. M. (1987). Isolation and structure determination of a diacetamidodideoxyuronic acid-containing glycan chain from the S-layer glycoprotein of Bacillus stearothermophilus NRS 2004/3a. Carbobydr Res 168, 211-218.

Munson, R. S. \& Glaser, L. (1981). Teichoic acid and peptidoglycan assembly in Gram positive organisms. In Biology of Carbohydrates, vol 1, pp. 91-122. Edited by V. Ginsburg \& P. Robbins. New York: Wiley.

Nagaoka, M., Kamisango, K.-I., Fujii, H., Uchikawa, K.-I., Sekikawa, I. \& Azuma, I. (1985). Structure of acidic polysaccharide from cell wall of Propionibacterium acnes strain C7. I Biochem 97, 1669-1678.

Piotto, M., Saudek, V. \& Sklenar, v. (1992). Gradient-tailored excitation for single-quantum NMR spectroscopy of aqueous solutions. J Biomol NMR 2, 661-665.

Ries, W., Hotzy, C., Schocher, I., Sleytr, U. B. \& Sára, M. (1997). Evidence for the $\mathrm{N}$-terminal part of the S-layer protein from Bacillus stearothermophilus PV72/p2 recognizes a secondary cell wall polymer. J Bacteriol 179 , 3892-3898.

Sára, M., Egelseer, E. M., Dekitsch, C. \& Sleytr, U. B. (1998). Identification of two binding domains, one for peptidoglycan and another for a secondary cell wall polymer on the N-terminal part of the S-layer protein SbsB from Bacillus stearothermophilus PV72/p2. J Bacteriol 180, 6780-6783.

Schäffer, C., Wugeditsch, T., Neuninger, C. \& Messner, P. (1996). Are S-layer glycoproteins and lipopolysaccharides related? Microb Drug Resist 2, 17-23.

Schleifer, K. H. \& Kandler, O. (1972). Peptidoglycan types of bacterial cell walls and their taxonomic implications. Bacteriol Rev 36, 407-477.

Schleucher, J., Schwendinger, M., Sattler, M., Schmidt, P., Schedletzky, O., Glaser, S. J., Sorensen, O. W. \& Griesinger, C. (1994). A general enhancement scheme in heteronuclear multidimensional NMR employing pulsed field gradients. $J$ Biomol NMR 4, 301-306.

Sklenar, V., Piotto, M., Leppik, R. \& Saudek, V. (1993). Gradienttailored water suppression for ${ }^{1} \mathrm{H}-{ }^{15} \mathrm{~N}$ HSQC experiments optimized to retain full sensitivity. J Magn Reson Ser A 102, 241-245.

Ward, J. B. (1981). Teichoic and teichuronic acids: biosynthesis, assembly and location. Microbiol Rev 45, 211-243.

van Zijl, P. C. M., Johnson, M. O., Mori, S. \& Hurd, R. E. (1995). Magic-angle-gradient double-quantum-filtered COSY. J Magn Reson Ser A 113, 265-270.

Received 24 December 1998; revised 8 March 1999; accepted 16 March 1999. 